\title{
Experimental and Simulation Testing of Flight Spin Stability for Small Caliber Cannon Projectile
}

\author{
Momčilo Milinović1,* - Damir Jerković2 - Olivera Jeremić1 - Mitar Kovač² \\ 1 University of Belgrade, Faculty of Mechanical Engineering, Serbia \\ 2 University of Defense, Military Academy, Serbia
}

The basic aim of this paper is to consider correlations of stability flight criteria, derived as the relations of aerodynamic coefficients and derivatives, on the model of a small caliber cannon spin stabilized projectile. Model of stability criteria calculations are performed by experimentally testing of aerodynamic data in the wind tunnel, and composed with the semi-empirical data, both applied on the flight trajectory stability simulation test. Authors' wind tunnel tests and calculated values of aerodynamic coefficients, as the function of Mach numbers of projectile model, are presented in the simulation flight trajectories stability criteria. The comparative analysis of experimental and calculated aerodynamic coefficients of projectile model is done, and refers to the stability flight criteria. Calculation of projectile aerodynamic Magnus moment derivatives, with other aerodynamic representatives, is used as the critical stability factors testing data vs. flight Mach numbers. Influences of this derivative absence and presence on the model sequence of the flight trajectory are presented for the estimation of angles of attack damping and stability factors. Simulation tests are presented for the supersonic and subsonic integral flight velocities and spin damping data. Research is realized due to the considerations of further projectiles correction possibilities on trajectory, and other new applications, vs. existing of unreliable lateral moments.

Keywords: aerodynamic coefficients spin stabilized small caliber cannon projectile, gyroscopic stability factor, dynamic stability factor, damping stability coefficients

\section{NOMENCLATURE}

$C_{M} \quad$ pitching moment coefficient, $M_{v} / Q S d$, [-],

$C_{M \alpha} \quad$ derivative of pitching moment coefficient, $\partial C_{M} / \partial \alpha,[-]$,

$C_{M a}$ derivative of pitch damping moment coefficient due to $q^{*}, \partial C_{M} / \partial q^{*},[-]$,

$C_{M \dot{\alpha}}$ derivative of pitch damping moment coefficient due to $\dot{\alpha}, \partial C_{M} / \partial \dot{\alpha},[-]$,

$C_{L} \quad$ lift (normal) force coefficient, $-F_{z} / Q S$, [-],

$C_{L \alpha} \quad$ derivative of lift force coefficient, $\partial C_{L} / \partial \alpha$, [-],

$C_{N} \quad$ yawing moment coefficient, $M_{z} / Q S d,[-]$,

$C_{M p \alpha}$ derivative of Magnus moment coefficient, $\partial^{2} C_{N} / \partial p^{*} \partial \alpha,[-]$,

$C_{D} \quad \operatorname{drag}\left(\right.$ axial) force coefficient, $F_{x} / Q S$, [-],

$C_{D 0} \quad$ zero angle drag coefficient, $\left(C_{D}\right)_{\alpha=0},[-]$,

$d$ reference diameter (caliber),

$I_{x} \quad$ axial moment of inertia, $\left[\mathrm{kg} \cdot \mathrm{m}^{2}\right]$,

$I_{y} \quad$ transverse moment of inertia, $\left[\mathrm{kg} \cdot \mathrm{m}^{2}\right]$,

$\bar{r}_{x} \quad$ relative axial radius of gyration, reversed to the caliber, $\left(I_{x} / m d^{2}\right)^{1 / 2},[-]$,

$\bar{r}_{y} \quad$ relative transverse radius of gyration reversed to the caliber, $\left(I_{y} / m d^{2}\right)^{1 / 2},[-]$,

$F_{x}, F_{y}, F_{z}$ forces along $x, y, z$ axes, [N],

$M_{x}, M_{y}, M_{z}$ moments about $x, y, z$ axes, $[\mathrm{N} \cdot \mathrm{m}]$,

$m$ mass of projectile, $[\mathrm{kg}]$,

$p \quad$ spin rate, $\left[\mathrm{s}^{-1}\right]$,

$p^{*} \quad$ reduced spin rate, $p d / V,[-]$,

$Q \quad$ dynamic pressure, $\rho V^{2} / 2,[\mathrm{~Pa}]$, $q \quad$ pitch rate, $\left[\mathrm{s}^{-1}\right]$,

$q^{*} \quad$ reduced pitch rate, $q d / V,[-]$,

$S \quad$ reference area, $\pi d^{2} / 4,\left[\mathrm{~m}^{2}\right]$,

$\alpha \quad$ angle of attack (pitch), $\left[{ }^{\circ}\right]$,

$\beta \quad$ angle of sideslip (yaw), $\left[{ }^{\circ}\right]$,

$\alpha_{t} \quad$ total yaw angle, approx. $\left(\alpha^{2}+\beta^{2}\right)^{1 / 2},\left[^{\circ}\right]$,

$\xi \quad$ complex angle of attack, $\alpha+i \beta,\left[{ }^{\circ}\right]$,

$\rho \quad$ atmospheric density, $\left[\mathrm{kg} / \mathrm{m}^{3}\right]$,

$\vec{V} \quad$ velocity vector of projectile, $[\mathrm{kg} / \mathrm{s}]$,

$u, v, w$ components of velocity along $x, y, z$ axes, $[\mathrm{m} / \mathrm{s}]$,

$H, P, T, M, G \quad$ Murphy's coefficients, [-],

$E=(\rho S d) /(2 m)$ reduction mass expression, [-],

$\mathrm{Sg} \quad$ gyroscopic stability factor, [-],

Sd dynamic stability factor, [-],

$\lambda_{1,2}$ damping stability coefficients, [-].

* denotes reduction of coefficients and derivatives $C_{i j}^{*}=C_{i j} E$.

\section{INTRODUCTION}

In the last twenty years the modern ammunition design, extended precision technology applications of guidance and control on the lower calibers of tactical ammunition. Analyses to be considered for guidance redesigning are especially challenging for the anti-aircraft (AA) cannon ammunition of smaller dimensions because of specific properties of projectiles flight, which have constraining 
possibilities of guidance technologies applications, [1] to [5]. Unguided AA projectile is, primarily, used for air targets, shooting with ballistic trajectories, but new considerations may also suppose its applications for the ground targets engaged from air and ground platforms in the so called close support operations.

Ballistic trajectory of AA gun projectile have significant changes of supersonic transonic and subsonic velocities during flight, from the very high initial to the much lower terminal values in the target impact point. Stable free ballistic flight of projectiles and stability criteria, determines attitudes of projectile axes towards the trajectory, [6] to [8]. It depends on aerodynamic shape, sensitivities on the drag and lift forces, aerodynamic moments their derivatives and spin rate stabilization efficiency vs. flight Mach numbers, but also of less discovered lateral Magnus moment and other artificial designed moments coupled with them, which changes on the flight trajectory.

The importance of experimental aerodynamically accurate estimations coupled with numerical stability criteria simulations is required because the spin stabilized symmetric AA cannon type projectile, exposes sensitive effects on the projectile stability which could influence conclusions about its novel applications and the redesign in the modernization considering processes.

A comparative analysis of calculated and experimental parameters is well known, proceeding for a preliminary estimation of all kinds of flight bodies, including flight vehicles with typical gyro - aerodynamics correlation loads, as in the [9] and [10] as rotary wings flight objects. Spin gyro - aerodynamics correlation loads, which strongly influenced on stability of flight projectiles, are referencing on the second class of flight bodies, known as the projectiles.

This paper deals with the aerodynamics of the spin projectile which is tested in the wind tunnel. The tested aerodynamics is compared with numerically predicted aerodynamic coefficients and derivatives. Both are used for the stability criteria analysis vs. Mach numbers.The simulated data are used from the AA gun model trajectory designed in [11] to [13].

\section{SPIN STABILIZED CRITERIA AND DATA REQUIREMENTS}

The key property of spin stabilized projectiles flight could be determined by the quality of its space spherical motion around the projectile body gravity center, during the flight on the ballistic trajectory. A very high spin of longitudinal axis and the low spin of the lateral disturbance provides gyro moment to stabilize projectile pitch. Composed spherical oscillations of body axes and direction of velocity vector, is question of stabilization [6] and [7]. As a result these lateral oscillations decrease perturbed amplitudes of total angle of attack if spin stabilization is successful, or increase if the projectile has not realized enough initial rpm by spin to form gyromoment for damping. Complex variable of the total angle of attack $\xi$, and its lateral angular motion due to the projectile body can be described by linearized differential equation derived by dimensionless distance instead of time as the main argument [6] in the form:

$$
\xi^{\prime \prime}+(H-i P) \xi^{\prime}-(M+i P T) \xi=-i P G,
$$

where $H, P, T, M$ and $G$ represents the so called Murphy's coefficient, [6] developed from the aerodynamic and dynamic solutions of the revolution body with gyroscopic low and high spin coupled motion. Since Eq. (1) is complex but linear, its solution is given as:

$$
\xi=\left(K_{10} e^{i \Phi_{10}}\right) e^{\left(\lambda_{1}+i \Phi_{1}^{\prime}\right) s}+\left(K_{20} e^{i \Phi_{20}}\right) e^{\left(\lambda_{2}+i \Phi_{2}^{\prime}\right) s}+\xi_{g} .
$$

Each value of the angular spin angles as the frequencies $\Phi_{j}^{\prime}$, and damping coefficients $\lambda_{j}$ in homogeneous solution, will vary with the relative magnitudes of the $H, P, T$ and $M$ which could be expressed as the basic function derived from the projectile designed form its aerodynamic, flight dynamic, inertial and all over flight performances. With an aim to separate conditions of damping abilities of a complex angle of attack expressed by $\lambda_{j}$, and gyroscopic frequencies effect $\Phi_{j}{ }^{\prime}$, the conditions of projectile's dynamic behavior of inertial axes, are enough precise approximately described in [6], [7] and [14], by assuming that $\Phi_{1}^{\prime} \Phi_{2}^{\prime}>>\lambda_{1} \lambda_{2}$.

This provides using a real solution to be applied and considered in the form:

$$
\Phi_{j}^{\prime}=\frac{1}{2}\left[P \pm \sqrt{P^{2}-4 M}\right], \quad j=1,2,
$$

and damping coefficient separated from joint solution as:

$$
\lambda_{j}=-\frac{1}{2}\left[H \mp \frac{P(2 T-H)}{\sqrt{P^{2}-4 M}}\right], \quad j=1,2 .
$$

Real values of both $\lambda_{j}$ and $\Phi_{j}^{\prime}$, Eqs. (3) and (4) determine gyroscopic stability criterion in the form:

$$
\frac{1}{S_{g}}=\frac{4 M}{P^{2}}
$$


where, $S_{g}>1$ as the obvious condition, from the Eq. (5), for the real roots in Eq. (3). Using aerodynamic coefficient [6] and [7] these expressions are determined by:

$$
S_{g}=\frac{I_{x}^{2} p^{2}}{2 \rho I_{y} S d V^{2} C_{M \alpha}}
$$

where,

$$
\begin{gathered}
P=\frac{I_{x}}{I_{y}} \cdot \frac{p d}{V}, \\
M=C_{M \alpha}^{*} \bar{r}_{y}^{-2} .
\end{gathered}
$$

The value of $S_{g}$ is known as the gyroscopic stability factor. A coupled requirement for the stability is that velocity vector angle of attack has to be damped. This is satisfied by the $\lim _{s \rightarrow \infty} \xi \rightarrow 0$, which requires a necessity that $\lambda_{1}$ and $\lambda_{2}$ are both negative $\lambda_{j}<0, \mathrm{j}=1,2$. This second condition evolves to the so called dynamic criterion of stability $S_{d}$ as referencing value in Eq. (4), in the form:

$$
S_{d}=\frac{2 T}{H},
$$

with values,

$$
\begin{gathered}
T=C_{L \alpha}^{*}+C_{M p \alpha}^{*} \bar{r}_{x}^{-2}, \\
H=C_{L \alpha}^{*}-C_{D}^{*}-\left(C_{M q}^{*}+C_{M \dot{\alpha}}^{*}\right) \bar{r}_{y}^{-2},
\end{gathered}
$$

where using aerodynamic properties [1], expression is:

$$
S_{d}=\frac{2\left(C_{L \alpha}+\bar{r}_{x}^{-2} C_{M p \alpha}\right)}{C_{L \alpha}-C_{D}-\bar{r}_{y}^{-2}\left(C_{M q}+C_{M \dot{\alpha}}\right)} .
$$

The condition that damping coefficients $\lambda_{j}$ have to be negative, relates to the following inequalities, respectively:

$$
H>0,
$$

and

$$
\left[\frac{P^{2}\left(S_{d}-1\right)^{2}}{P^{2}-4 M}\right]<1 .
$$

These Eqs. (13) and (14) coupled with Eq. (5) gyroscopic conditions $S_{g}>1$, finally give stability expression inequality as:

$$
\frac{1}{S_{g}}<S_{d}\left(2-S_{d}\right)
$$

Eq. (15) describe general criteria of dynamic stability for any axis-symmetric projectile spin or fin equipped. According to [6] to [8], the stability criteria Eqs. (6) and (12) are developed in relation to aerodynamic coefficients and derivatives coupled by inertial and dynamic properties of the body motion. Eqs. (7), (8), (10) and (11) appears as the conditionally for the aerodynamic behavior of projectile's forces and moments as the loadings expressed by the Murphy's coefficients, in the Eq. (1) vs. flight Mach numbers, angle of attack, and the so called derivatives in the changes during flight, [6]. Spin stabilized projectiles during the real flight, change damping coefficients Eq. (4) of characteristic Eq. (2), $\lambda_{1}$ and $\lambda_{2}$, and also factors of stability, $S_{g}$, given by Eqs. (5) and (6), and $S_{d}$, given in Eqs. (9) and (12), which is further derived. The calculated data are used in changes of stability criteria estimations at the expected muzzle distances after firing from the cannon barrel, [13].

For AA cannon projectile of small caliber this spin stabilized behavior vs. flight Mach number will be considered further as a result of experimental testing of measured aerodynamic coefficients and appropriate semi empirical and theoretical data in the stability criteria Eqs. (6) and (12). The aim is to discover influence of the longitudinal position of lateral aerodynamic Magnus force over derivative of Magnus moment coefficient $C_{M p \alpha}$, on the spin stabilizing factors, which changes its values vs. flight Mach number from high supersonic to the high subsonic values.

Considerations have been made using the condition in Eqs. (6) and (12), by the complex simulation in redesigned basic software showed in [8], [11] and [13].

\section{BASE EXPERIMENTAL EQUIPMENT AND TESTING MODEL SET UP}

The base experimental equipment used for aerodynamic simulation was the three-sonic wind tunnel test facility T-38, [15]. The tunnel is a blow down pressurized type with a $1.5 \times 1.5 \mathrm{~m}$ square test section, aimed for subsonic and supersonic tests, [15]. The tunnel was fully equipped by appropriate equipment to simulate flight flow conditions.

Mach number can be set and regulated to within $0.5 \%$ of the required value. Total pressure in the test is within $1.1 \times 10^{5}$ to $15 \times 10^{5} \mathrm{~Pa}$ regulated to $0.3 \%$ errors of real flight conditions. Run times are in the range 6 to $60 \mathrm{~s}$, depending on Mach number and total pressure. The facility supports, step-by-step model movement 
and continuous movement of model ("sweep mode") during the measurements.

Simulation and experimentally tested model of projectile in the tunnel is shown on the Fig. 1, [13]. Characteristic values of mass and dimensions, approximately, corresponds to the AA cannon 40 mm HE unguided projectile, Table 1. The model is supported in the test section by a tail sting mounted on a pitch simulation mechanism by which desired aerodynamic angle can be achieved.

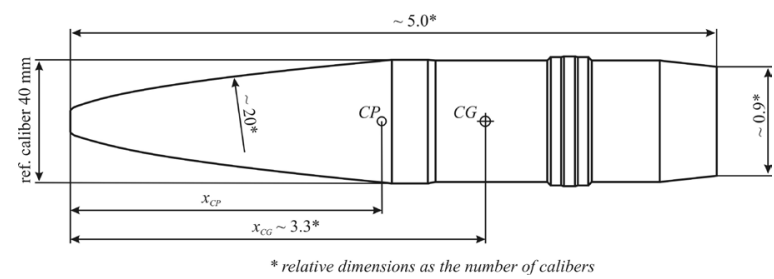

Fig. 1. Model of spin stabilized projectile

Table 1. Model of projectile [13]

\begin{tabular}{lcc}
\hline Parameter & Symbol, unit & Value \\
\hline Reference diameter (cal) & $d[\mathrm{~mm}]$ & 40 \\
\hline Total length & $I[-]$ & $\sim 5^{\star}$ \\
\hline Nose length & $I_{1}[-]$ & $\sim 2.5^{\star}$ \\
\hline Ogive radius & $R_{0}[-]$ & $\sim 20^{*}$ \\
\hline Boat tail length & $I_{3}[-]$ & $\sim 0.5^{\star}$ \\
\hline Center of mass & $x_{C G}[-]$ & $\sim 3.3^{*}$ \\
\hline Mass of projectile & $m[\mathrm{~kg}]$ & $\sim 1.0$ \\
\hline Axial inertia moment & $I_{x}\left[\mathrm{~kg} \mathrm{~m}{ }^{2}\right]$ & $\sim 2.1 \cdot 10^{-4}$ \\
\hline Transversal inertia moment & $I_{y}\left[\mathrm{~kg} \mathrm{~m}{ }^{2}\right]$ & $\sim 2.3 \cdot 10^{-3}$ \\
\hline * relative values as number of reference diameter (caliber)
\end{tabular}

Tests on the model were performed in the Mach number range from 0.2 to 3.0 (14 different values of Mach number). The simulated total angles of attack $\alpha_{t}$, redefined to the angle of attack in vertical plane, $\alpha$, (pitch angle, as a good approximation to the total yaw angle, pp. 33, [6]), were in the interval, -10 to $+10^{\circ}$, [12] and [13]. Test conditions were given in Table 2. Aerodynamic forces and moments of the model were measured by ABLE 1.00 MKXXIIIA internal sixcomponent strain gauge balance, [13] and [15]. The nominal load range of the balance was $2800 \mathrm{~N}$ for normal, $620 \mathrm{~N}$ for side forces, $134 \mathrm{~N}$ for axial force, $145 \mathrm{Nm}$ for pitching, $26 \mathrm{Nm}$ for yawing moment and $17 \mathrm{Nm}$, for static spin damping moment; the accuracy was approximately $0.25 \%$ F.S. for each component. Instrumentation and data recording were performed after each run using the standard T38-APS software [15] in several stages, i.e.: Data acquisition system interfacing and signal normalization; Determination of flow parameters in the test section of the wind tunnel;
Determination of the model position (orientation) is relative to test section and airflow. Determination of non-dimensional aerodynamic coefficients of forces and moments for each stage has been performed by appropriate tunnel tests, different software modules, [17].

Table 2. Test conditions [13]

\begin{tabular}{lcc}
\hline Parameter & Symbol, unit & Value \\
\hline static pressure & $p_{S}[\mathrm{~Pa}]$ & $0.2 \times 10^{5}$ to $2.2 \times 10^{5}$ \\
\hline stagnation pressure & $p_{0}[\mathrm{~Pa}]$ & $2.3 \times 10^{5}$ to $6 \times 10^{*}$ \\
\hline atm. temperature & $T_{\text {atm }}[\mathrm{K}]$ & $\approx 280$ \\
\hline Mach number & $M a[-]$ & 0.2 to 3 \\
\hline Re number & $R e[-]$ & $0.5 \times 10^{6}$ to $2 \times 10^{6}$ \\
\hline angle of attack (pitch) & $\alpha\left[^{\circ}\right]$ & -10 to 10 \\
\hline${ }^{*}$ for all Mach numbers was $2.3 \cdot 10^{5} \mathrm{~Pa}$, since for $\mathrm{Ma}=2.5$, \\
$p_{0}=4 \cdot 10^{5} \mathrm{~Pa}$ and $\mathrm{Ma}=3, p_{0}=6 \cdot 105 \mathrm{~Pa}$. \\
\hline
\end{tabular}

\section{EXPERIMENTAL RESULTS AND SPIN STABILIZED MODELING}

\subsection{Aerodynamic Coefficients and Derivatives}

The characteristic functions of aerodynamic coefficients in relation to the flight Mach numbers and angles of attack $\alpha$, measured in the author's testing, [13] in the wind tunnel is presented in Figs. 2 to 5, and Fig. 6 represents additional data supposed from [14]. The influenced aerodynamic coefficients tested on the projectile model are aerodynamic coefficient of drag force, Fig. 2, derivative of lift force coefficient presented in Fig. 3, derivative of pitching moment coefficient given in Fig. 4, and all vs. flight Mach number. Flight Mach numbers were corresponding to the projectile flight velocities on the modeling trajectories. Aerodynamic prediction or calculations of coefficients and derivatives are determined with two semi-empirical methods: ADK0 for zero angle drag coefficient and ADK1 for others, [13]. Research was developed according to [11] and [16] to [18]. Data of these predictions for appropriate aerodynamic coefficients are also presented in the same figures and compared with the above mentioned experimental values. Aerodynamic coefficients vs. side slip component of total yaw angle $\beta$, was not tested experimentally and further considerations took these effects in integral yaw angle, by semi-empirical predictions denoted as ADK1 in the previously mentioned references. Measurements of the so called dynamic derivatives of pitch damp coefficient in wind tunnel facilities require complex and expensive testing equipment, and improvement of the test model design, which were not used in these experiments. 
Experiments of pitch derivatives, vs. flight Mach numbers are approximately determined in the tunnel test simulations using the test model pitch motion, with threshold ability of angular rate in sweep-mode as was 2 degrees per second, [12] and [13]. Values of derivatives of aerodynamic coefficient $C_{M q}+C_{M \dot{\alpha}}$, realized in these experiments are presented in Fig. 5, by dot-points curve realized in the singular flight test runs, vs. 14 values of simulated flight Mach numbers. A comparison of these values with the data calculated by ADK1 prediction is also presented in the same figure.

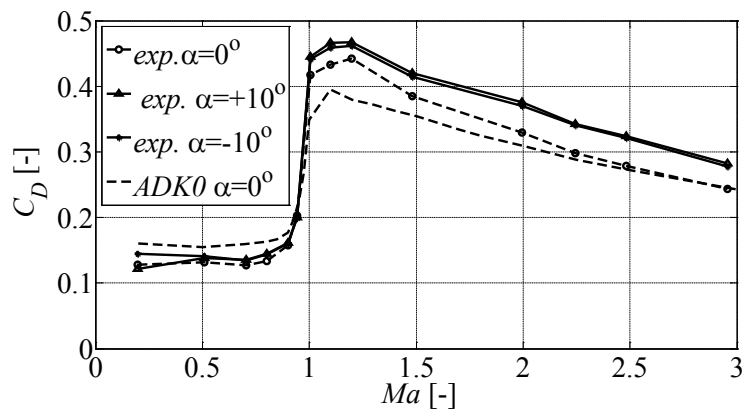

Fig. 2. Predicted values (ADKO) and experimental values (exp.) of drag coefficients

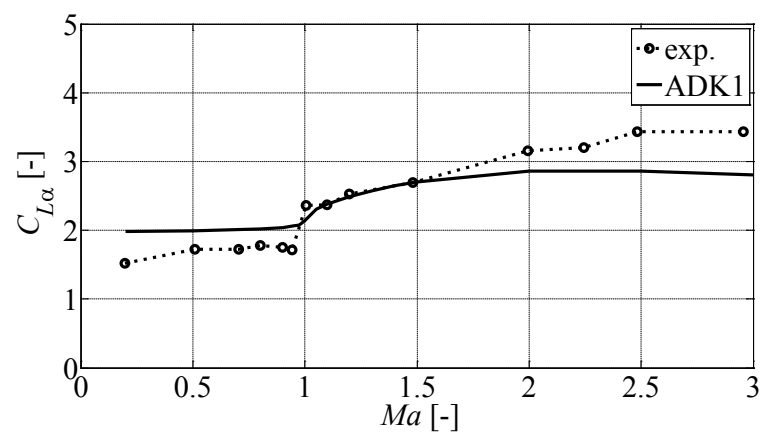

Fig. 3. Predicted values (ADK1) and experimental values (exp.) of derivative of lift force coefficient

The derivative of Magnus moment coefficient, $C_{M p a}$, which could not be simulated by the wind tunnel was estimated by calculations from the approximated model ADK1, [13] according to the developed estimations in [6], [7] and [14], Fig. 6. Variations are accepted based on data in [6], [7], [11] and [14]. It was the base challenge in estimation because Magnus force effects influenced the stability similarly as any other lateral force and is composed of flight Mach number effect and spin peripheral velocity designed in the stream flow. This aerodynamic loading coefficient based on the relative small values of real Magnus forces could make undetermined problems to the stability of projectiles if the force lateral position along longitudinal axes is not well known, or vary vs. flight Mach numbers changes. Flight Mach numbers and other data are changed on the simulated trajectory by the six degrees of freedom software (6DOF) [6], [8], [11] and [13] modeling.

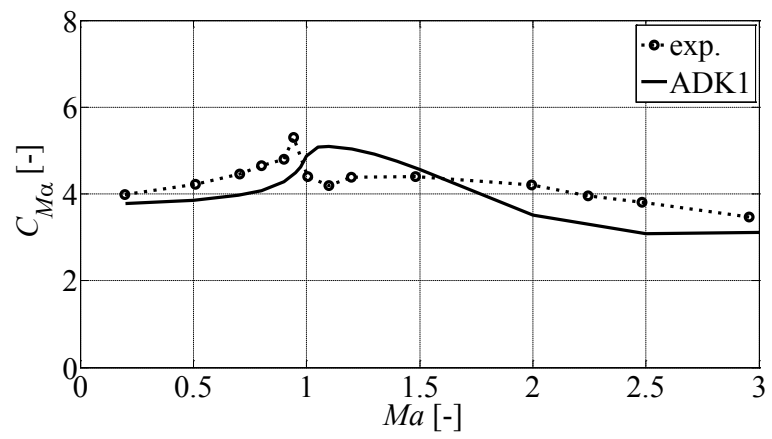

Fig. 4. Predicted values (ADK1) and experimental values (exp.) of derivative of pitching moment coefficient



Fig. 5. Predicted values (ADK1) and simulated experimental values (exp.sim.) of dynamic derivative of pitch damping moment

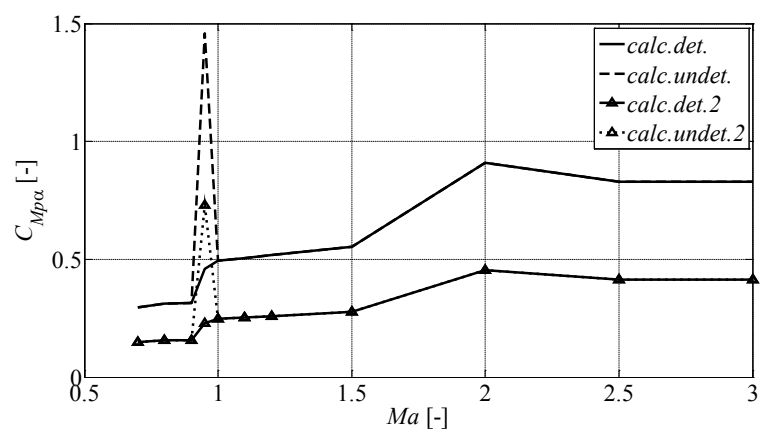

Fig. 6. Predicted values (ADK1) of derivative of Magnus moment coefficient [14]

The flight conditions are given in Table 3. Aerodynamic data have been estimated by ADK0, ADK1 and presented from experimental tests.The estimated main derivatives were assumed as the challenge for sensitivity tests of the so called stability vs. flight Mach number, represented velocities on any type of trajectory. 
Table 3. Flight simulation condition [13]

\begin{tabular}{lcc}
\hline Parameter & Symbol, unit & Value \\
\hline pressure & $p_{a}[\mathrm{~Pa}]$ & $1.01310^{5}$ \\
\hline temperature & $T_{a}[\mathrm{~K}]$ & 288.13 \\
\hline muzzle velocity & $V[\mathrm{~m} / \mathrm{s}]$ & 985 \\
\hline $\begin{array}{l}x \text { component of muzzle angular velocity } \\
\text { - spin }\end{array}$ & $p\left[\mathrm{~s}^{-1}\right]$ & 6300 \\
\hline$y$ component of muzzle angular velocity & $q\left[\mathrm{~s}^{-1}\right]$ & $1.0^{* \star}$ \\
\hline$z$ component of muzzle angular velocity & $r\left[\mathrm{~s}^{-1}\right]$ & $7.7^{* \star}$ \\
\hline Table range angle (gun elevation) & $\theta_{0}\left[{ }^{\circ}\right]$ & 5 to 20 \\
\hline ** according to the research of the initial fire disturbing conditions, \\
[11] and [13]
\end{tabular}

\subsection{Spin Stability Parameters Modeling}

Qualitative evaluation of projectile stability is determined through an analysis of the simulated data using software 6DOF, [11] and [13], expressed in the following:

- $\quad$ absolute values of total angle of attack $\left|\alpha_{t}\right|$ vs. time, Fig. 7, which corresponds to the solution of $|\xi|$ in Eq. (2), with zero initial $\xi_{g}$,

- damping behavior $\lambda_{1,2}$, of high and law spin of complex $|\xi|$ module, vs. stability factors relation Figs. 8a and b, all vs. flight Mach number,

- gyroscopic stability factor $S_{g}$ and criteria relation, Fig. 9,

- $\quad$ spin angular velocity damping $p$, Fig. 10,

- dynamic stability factor $S_{d}$ and criteria, Figs. 11 and 12 ,

- $\quad$ total stability criteria Fig. 13.

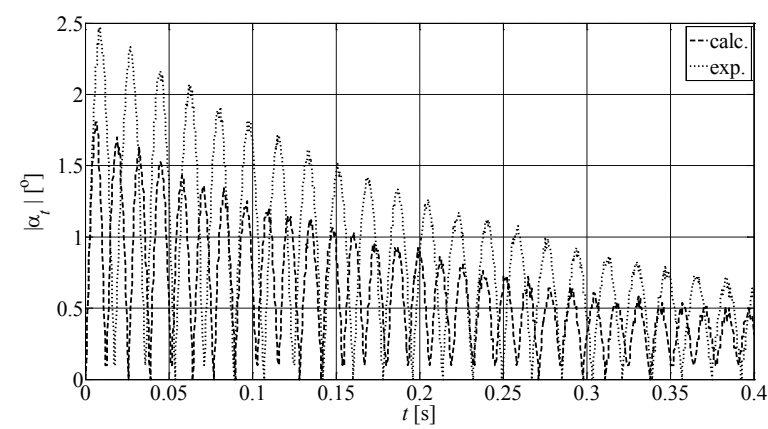

Fig. 7. Absolute simulated angle of attack on the initial part of trajectory

Two groups of aerodynamic data in flight projectile stability modeling are used, as well as calculated data, (ADK1) denoted in Figs. 8 to 13, as the (calc.) and experimental aerodynamic data used from Figs. 2 to 6, composed in the matrix form adapted for the software, and denoted as the (exp.) roots simulations. Experimental rooted data, of $\alpha_{t}$, corresponded to the tunnel measured values vs. angles of attack $\alpha$.

Complex yaw simulations taken from the calculated data and with a total yaw angle $\alpha_{t}$, composed from vertical (pitch) angle of attack $\alpha$ are simulated to prove the damping effect of velocity direction to the projectile body, which was preliminarily designed by simulation without derivative of Magnus moment coefficient, which means Magnus force point is in the center of mass. Representative damping quality should be exposed at the very beginning of flight within less than half a second, Fig. 7. These influences caused by Murphy's coefficient $H$ were dominant aerodynamic derivatives calculated estimations and experiments shown in Fig. 5, as the summary dynamic derivatives of coefficient $C_{M q}+C_{M \dot{\alpha}}$, in both, supersonic and subsonic flight Mach numbers, expressed deviations of more than 30 percent for calculated and experimental data. This causes a strong influence on Eq. (11), in the simulation done using static tunnel test data, which was performed by inappropriate derivative measurements. Differences of experimental and calculated data from the initial flight Mach numbers of about 3 to 1.5, are caused in the derivative of pitch damp moment coefficient $C_{M \alpha}$, Fig. 4, which strongly influenced $S_{g}$ estimations by calculated and experimental data, Fig. 9. This was significantly exposed for the high initial flight Mach numbers. Approval is shown in Fig. 9 where both gyro stability curves factors and criteria of the calculated and experimental roots make a crossing in the Mach number of 1.5 values. This is in correlation to the values of Fig. 4.

Other related influences on the differences of the angle like the Magnus force and their lateral position along projectile longitudinal axis, affected the side-slip component $\beta$ in the total yaw angle $\alpha_{t}$ were not considered but were performed through influencing estimations in the stability factors and damping performances in the gyro stabilization. The angle damping behavior vs. flight Mach numbers, Fig. 7 correlated with the measurement in flight tunnel tests and calculated data with the derivative of Magnus moment coefficient $C_{M p \alpha}$, Fig. 6, influences are presented in Fig. 8b, expresses negative and $8 \mathrm{a}$, one negative and one positive values of damping coefficients Eq. (4). These data have shown disastrous influencing of derivative of Magnus moment coefficient $C_{M p \alpha}$, which was tested, using Fig. 6 values by $100 \%$ variations, keeping the same other conditions in the stability tests. This means more an unknown position of Magnus force along projectile axis than their intensity values. The 


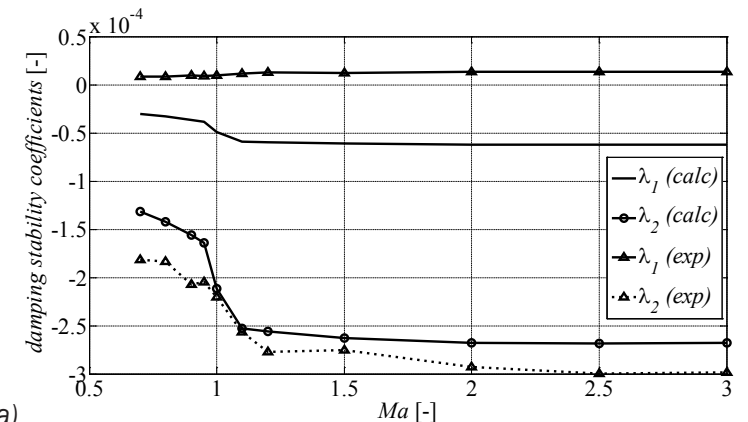

a)

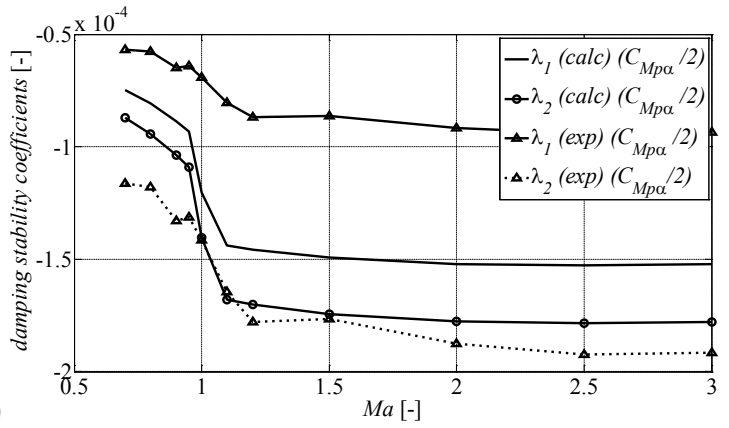

Fig. 8. Damping coefficients vs. Mach number; a) for full value of derivative of Magnus moment coefficient, b) for half value of derivative of Magnus moment coefficient

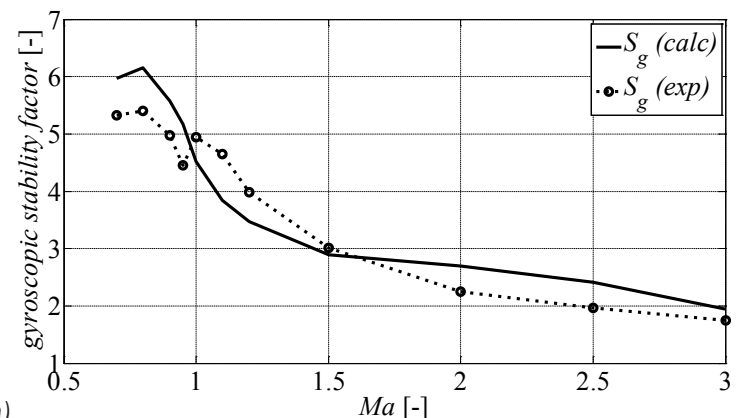

a)

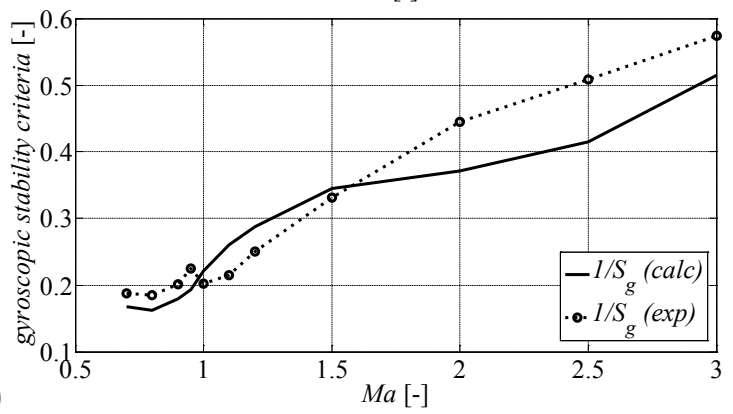

Fig. 9. Gyroscopic stability relation vs. Mach number; a) gyroscopic stability factor, b) gyroscopic stability criteria

differences between experimental and the calculated data vanished by decreasing this derivative vs. Mach number distribution, Fig. 8b. This effect is caused by coupling with estimations of $H$, Murphy's coefficient, Eq. (10), which remains positive values, Eq. (13), but vary, making influences on the $\lambda_{1,2}$, more on the high

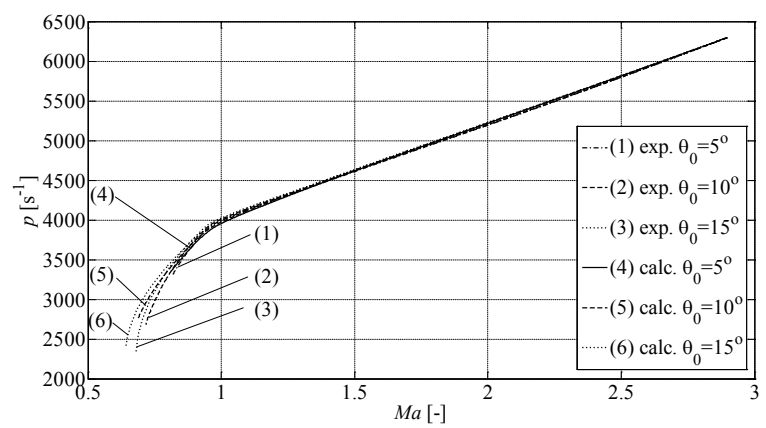

Fig. 10. Angular spin velocity vs. Mach number

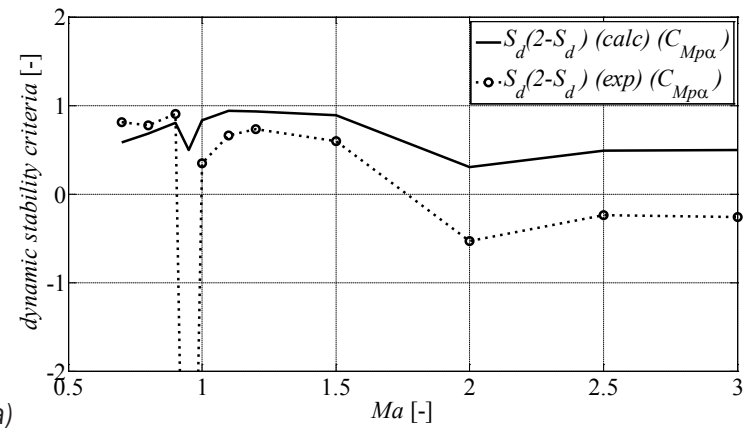

a)

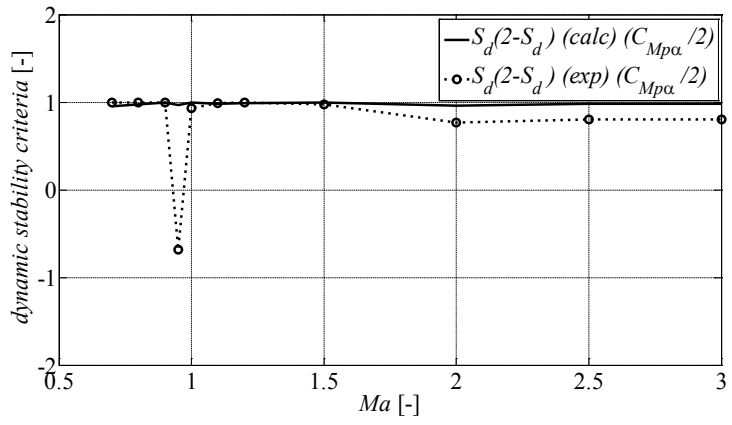

Fig. 11. Dynamic stability relation criteria vs. Mach number; a) for full value of derivative of Magnus moment coefficient, b) for half value of derivative of Magnus moment coefficient

frequency damping coefficient $\lambda_{1}$ then on the $\lambda_{2}$, low frequency damping coefficient, both expressed in the in Eq. (4).

Gyroscopic stability factor determined by the changes of flight Mach number and the data of the projectile model are presented in Fig. 9 demonstrates flight gyro-stability factor as a relation of Eq. (6) vs. Mach numbers not violated by the derivatives.

The spin velocity, projectile performances are taken in both data types of simulations representative trajectory with equal values vs. Mach number, represented in Fig. 10, and corresponding with projectile model data in Tables 1 and 3 .

Changes of spin were not tested experimentally. The most significant influences of the derivative of Magnus moment coefficient $C_{M p \alpha}$, Fig. 6, were 
exposed as disastrous on the estimated calculations of dynamic stability factors. In the presented Figs. 11 and 12, the condition of dynamic stability Eq. (15), and stability factor given by Eq. (12) with Magnus moment derivative influences were tested. Influencing of the derivative of Magnus moment coefficient $C_{M p \alpha}$, which varied $100 \%$ in Fig. 6, making the stability of the dynamic factor bigger than 2 thus, making Eq. (15) negative, Fig. 12, and violating stability. Double less values of $C_{M p \alpha}$ vs. flight Mach numbers rearranged the stability of dynamic factors, but making neutral stability approximately. Effects are related to the values of $H$ also by modestly reliable data, taken as the sum of derivatives $C_{M q}+C_{M \dot{\alpha}}$. The sum is shown as influence on the dynamic stability in Fig. 12, with respectable differences between the simulated stability criteria in Eq. (12), with experimental and calculated data vs. Mach number. Values are exposed as the coupled with $C_{L \alpha}$ influences and the above mentioned derivatives.

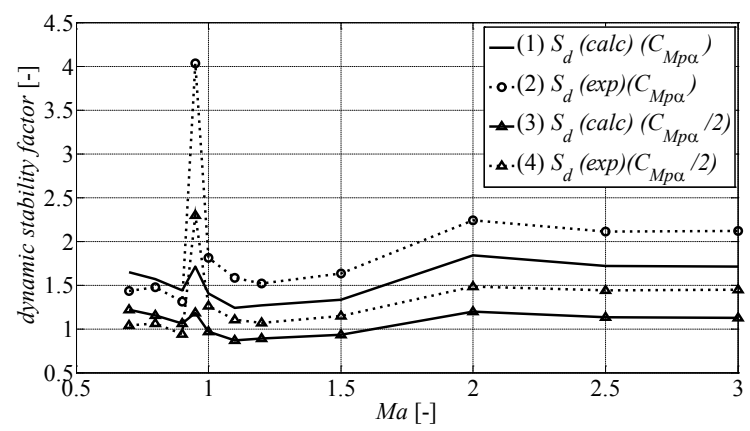

Fig. 12. Influences of derivative of Magnus moment coefficient on dynamic stability factor

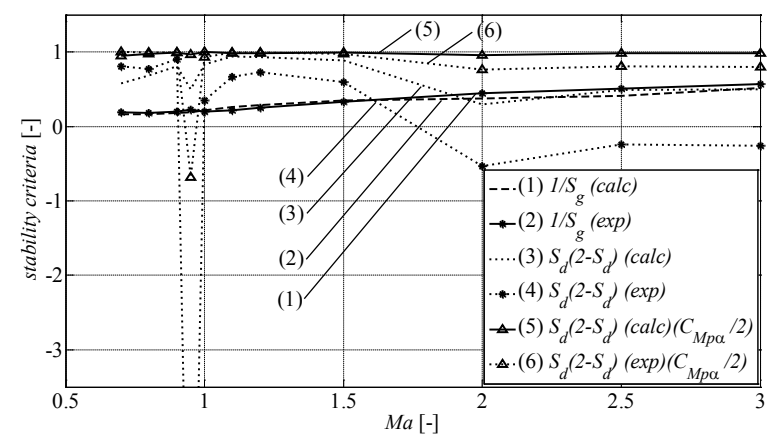

Fig. 13. Total stability factors equation influences for full and half derivative of Magnus moment coefficient vs. Mach number

Dynamic stability factor $S_{d}$ and gyroscopic stability factor $S_{g}$ related by Eq. (15) are presented in Fig. 13 as the final value of stability testing influences vs. Mach number tests and simulations. The main differences of the experimental and calculated data denoted expected total stability of projectile in the flight. The coupled effect in Fig. 13 proves that the dominant role of the estimated positive values $C_{M p \alpha}$ of about 0.8 to 0.4 , in supersonic and subsonic flight has a negative effect on the projectile flight stability.

Table 4. Approximate estimations of aerodynamic parameters' influences on stability parameters [13]

\begin{tabular}{|c|c|c|c|}
\hline $\begin{array}{c}\mathrm{AD} \\
\text { parameter }\end{array}$ & $\begin{array}{c}\text { Manner of } A D \\
\text { parameter }\end{array}$ & $\begin{array}{c}\text { Stability } \\
\text { parameter }\end{array}$ & $\begin{array}{c}\text { Sensitivity of stability } \\
\text { parameter }\end{array}$ \\
\hline \multirow{8}{*}{$C_{D 0}$} & \multirow{4}{*}{ increasing } & $\lambda_{2}$ & increase to $20 \%$ \\
\hline & & $1 / S_{g}$ & increase to $20 \%$ \\
\hline & & $S_{d}\left(2-S_{d}\right)$ & increase to $5 \%$ \\
\hline & & $p$ & decrease 3 to $8 \%$ \\
\hline & \multirow{4}{*}{ decreasing } & $\lambda_{2}$ & decrease to $20 \%$ \\
\hline & & $1 / S_{g}$ & decrease to $20 \%$ \\
\hline & & $S_{d}\left(2-S_{d}\right)$ & decrease to $5 \%$ \\
\hline & & $p$ & increase 3 to $8 \%$ \\
\hline \multirow{4}{*}{$C_{L \alpha}$} & \multirow{2}{*}{ increasing } & $\lambda_{2}$ & increase to $20 \%$ \\
\hline & & $S_{d}\left(2-S_{d}\right)$ & increase to $5 \%$ \\
\hline & \multirow{2}{*}{ decreasing } & $\lambda_{2}$ & decrease to $20 \%$ \\
\hline & & $S_{d}\left(2-S_{d}\right)$ & decrease to $6 \%$ \\
\hline \multirow{2}{*}{$C_{M \alpha}$} & increasing & $1 / S_{g}$ & increase to $15 \%$ \\
\hline & decreasing & $1 / S_{g}$ & decrease to $15 \%$ \\
\hline \multirow{4}{*}{$\begin{array}{l}C_{M q}+ \\
C_{M \dot{\alpha}}\end{array}$} & \multirow{2}{*}{ increasing } & $\lambda_{1}$ & decrease to $30 \%$ \\
\hline & & $S_{d}\left(2-S_{d}\right)$ & decrease 2.5 to $7 \%$ \\
\hline & \multirow{2}{*}{ decreasing } & $\lambda_{1}$ & increase to $30 \%$ \\
\hline & & $S_{d}\left(2-S_{d}\right)$ & increase to $8 \%$ \\
\hline \multirow{4}{*}{$C_{M p \alpha}$} & \multirow{2}{*}{ increasing } & $\lambda_{1}, \lambda_{2}$ & increase to $30 \%$ \\
\hline & & $S_{d}\left(2-S_{d}\right)$ & increase to $25 \%$ \\
\hline & \multirow{2}{*}{ decreasing } & $\lambda_{1}, \lambda_{2}$ & increase to $30 \%$ \\
\hline & & $S_{d}\left(2-S_{d}\right)$ & increase to $25 \%$ \\
\hline
\end{tabular}

These data correspond with [13] but do not fully correspond with [14], and are directed to general conclusions in [6], which are that Magnus moment effect could be expected to be suspicious if it is taken from the data which are not proved by real measurements which are missed in the published data. The paper confirms estimations of instability boundaries and area of main derivative coupling influenced on the flight. Lateral force in the center of gravity proves determination of the stable flight. An Increase of lateral moment derivatives caused by a variation of the force center along the projectile axis is not suggested. Sensitivity of stability factors tested in [13] and in this paper is presented in Table 4.

\section{CONCLUSION}

The stability of AA gun projectile model is affected by aerodynamic coefficients and derivatives through their steady state testing data. The test performed by 
an approximately real designed model of projectile was used, and the obtained measurements are valid but not enough for the full reliable estimations of flight stability. The trait of the change of the based calculated values of aerodynamic coefficients coincides with the experimental results of aerodynamic coefficients but does not satisfy the required conclusions about the stability without derivative measurements. A comparative calculation model of coefficient estimations is tested to prove possible indeterminations which could appear as significant, but were not present in the measurement on the tunnel tests at approximately steady state conditions. Further research of ammunition correction functions could be possible for preliminary consideration by simulated stability methodology of lateral forces required in correction by the method of coefficient derivatives shown in this paper. Damping efficiency of projectile initial magnitude of angle velocity vector $\alpha_{t}$ (total yaw angle) is about 0.4 seconds after launching, which corresponds to the expected if lateral force is in the center of mass. Also, sensitivity tests give satisfied frame values of gyroscopic stability and dynamic stability influences for the approximated values of Magnus moments and other similar disturbances representatively arranged in the coefficient derivatives values. Further research should comprise of simulations and a test to develop the best way for ammunition guidance considerations based on the behavior of the main projectile axes and velocity vector during flight. Further dynamic testing of aerodynamic derivatives requires appropriate tunnel facility including equipment for a good simulation of the angular motion for ammunition models tests.

\section{AKNOWLEDGMENT}

The results presented in this paper are made within project No III47029 financed by Ministry of Science and Technology Development of the Republic of Serbia.

\section{REFERENCES}

[1] Regan, F.J. (1975). Aeroballistics of terminally corrected spinning projectile (TCSP). Journal of spacecraft, vol. 12, no. 12, p. 733-738.

[2] Morrison, P.H., Amberntson, D.S. (1977). Guidance and control of a cannon-launched guided projectile. Journal of spacecraft, vol. 14, no. 6, p. 328-334.

[3] Zarchan, P. (1990). Tactical and strategic missile guidance. Progress in Astronautics and Aeronautics, $A I A A$, vol. 124.
[4] Vogt, R., Glebocki, R. (2000). Impulse control of anti-tank mortar missile. RTO AVT Symposium on Active Control Technology for Enhanced Performance Operational Capabilities of Military Aircraft, Land Vehicles and Sea Vehicles, Braunschweig.

[5] Gupta, S.K., Saxena, S., Singhal, A., Ghosh, A.K. (2008). Trajectory correction flight control system using pulse jet on artillery rocket. Defense Science Journal, vol. 58, no. 1, p. 15-33.

[6] McCoy, R.L. (1999). Modern exterior ballistics. Schiffer Military History, Atglen.

[7] Carlucci, D.E., Jacobson, S.S. (2008). Ballistics Theory and design of guns and ammunition. CRC Press, Boca Raton.

[8] Regodić, D. (2006). Exterior ballistics. Military academy, Belgrade. (in Serbian)

[9] Mitrović, Č., Bengin, A., Cvetković, D., Bekrić, D. (2010). An optimal main helicopter rotor projection model obtained by viscous effect and unsteady lift stimulation. Strojniški vestnik - Journal of Mechanical Engineering, vol. 56, no. 6, p. 357-367.

[10] Petrović, Z., Stupar, S., Kostić, I., Simonović, A. (2010). Determination of a light helicopter flight performance at the preliminary design stage. Strojniški vestnik - Journal of Mechanical Engineering, vol. 56, no. 9, p. 535-543.

[11] Regodić, D. (2003). Exercises in exterior ballistics. Military academy, Belgrade. (in Serbian)

[12] Jerkovic, D., Samardzic, M. (2008). The aerodynamic characteristics determination of classic symmetric projectile. The $5^{\text {th }}$ international symposium about design in mechanical engineering, KOD, p. 275-282.

[13] Jerković, D. (2009). The influence of aerodynamic coefficients on the motion of axis-symmetrical body. Faculty of technical sciences University of Novi Sad. (in Serbian)

[14] Regan, F.J., Schermerhorn, V.L. (1971). Aeroballistic evaluation and computer stability analysis of the US Navy 20-mm general purpose projectile. NOLTR, p. 71-95.

[15] Elfstrom, G.M., Medved, B. (1986). The Yugoslav 1.5 $\mathrm{m}$ trisonic blowdown wind tunnel. 14th Aerodynamic Testing Conference. West Palm Beach, AIAA Paper 8624726, p. 89-95.

[16] Krasnov, N.F. (1985). Aerodynamics 1 - Fundamentals of Theory. Mir Publishers, Moscow.

[17] Krasnov, N.F. (1985). Aerodynamics 2 - Methods of Aerodynamic Calculations. Mir Publishers, Moscow.

[18] Janković, S. (1979). Aerodynamics of projectiles, Faculty of mechanical engineering, Belgrade (in Serbian)

[19] McCoy, R.L. (1985). Aerodynamic and flight dynamic characteristics of the new family of $5.56 \mathrm{~mm}$ NATO ammunition. Memorandum report BRL-MR-3476, US Army Ballistic Research Laboratory, Aberdeen Proving Ground, Maryland. 